Available online on 15.05.2020 at http://jddtonline.info
Open Access to Pharmaceutical and Medical Research
unrestricted non-commercial use, provided the original work is properly cited

Open $\odot$ Access

Review Article

\title{
Articulation of Quality By Design Elements for Product Development and its Unique Applications
}

\author{
Sitre Dnyaneshwar*, Kamble Ravindra \\ 1Dept. of Pharmaceutics, Bhupal Nobles University, Maharana Pratap Station Road, Udaipur 313001, Rajasthan, India
}

\begin{abstract}
Quality by Design (QbD) is a methodical approach to pharmaceutical product development that begins with predefined objectives and emphasizes product and process comprehension and process control based on sound science and quality risk management. Pharmace utical development should lead to the design a quality product and its manufacturing process to meet the QTPP and CQA parameters. To arrive at the robust product development $\mathrm{QbD}$ articulation is important which is missing in most of the reviews. This review articulates the QbD elements in the product development. QbD process stars with identification of QTPP and source CQA from QTPP. CMAs and CPPs are derived with risk assessment from the product ingredients and process. Their impact on the CQAs can be studies with DoE tools. The information and knowledge gained from pharmaceutical development studies and manufacturing experience provide scientific understanding to support the design space and control strategy. Product process follows life cycle management approach with continuous improvement. PAT tools are utilized for the online monitoring of the processes. This review paper is dedicated to provide QbD element articulation in product development and its unique applications in the various areas of the product development such as Biotechnology, Nanotechnology products, Nasal products, Inhalation, Injectable products, Targeted drug delivery, complex Solid oral, Transdermal and topical products, Bioavailability and dissolution enhancement, Analytical processes and API manufacturing etc. Current trends in the technical application of the PAT tools are discussed.
\end{abstract}

Keywords: Quality by Design (QbD), Quality Target Product Profile (QTPP), Critical Quality Attributes (CQA) and Design of Experiment (D oE): Product development application of QbD

Article Info: Received 18 March 2020; Review Completed 21 April 2020; Accepted 27 April 2020; Available online 15 May 2020

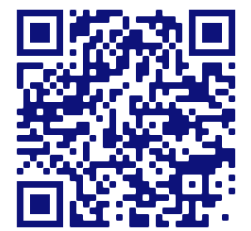

Rajasthan, India
Cite this article as:

Sitre D, Kamble R, Articulation of Quality By Design Elements for Product Development and its Unique Applications Journal of Drug Delivery and Therapeutics. 2020; 10(3):253-261 http://dx.doi.org/10.22270/jddt.v10i3.4080

\section{*Address for Correspondence:}

Dnyaneshwar Sitre, Dept. of Pharmaceutics, Bhupal Nobles University, Maharana Pratap Station Road, Udaipur 313001,

\section{Introduction}

Quality by Design (QbD) has supported both industry and FDA to achieve scientific, risk based, and proactive approach to pharmaceutical product development. [1] The $\mathrm{QbD}$ is a systemic approach to pharmaceutical product development which leads to formulations and manufacturing processes with desired quality attributes. [2] Pharmaceutical QbD may include achieving meaningful control strategy that are based on clinical performance to increase process capability by enhancing product and process design. [3] The theme of $\mathrm{QbD}$ is Quality can't be tested into the product, but it should be built into it. [4]

Studies have shown that the Lifecycle management approach for the product development supports establishment of the design space and working within design space is not considered as change by the regulatory agencies. [5] The International Council for Harmonisation of Technical Requirements for Pharmaceuticals for Human Use (ICH) guidelines ICH Q8 (Pharmaceutical Development), ICH Q9 (Quality Risk Management) and ICH Q10 (Pharmaceutical Quality Systems) are basis for the QbD in product development to achieve the quality product. [6] Prime requirement for the $\mathrm{QbD}$ implementation are to establish relationship of the product CQAs with CMAs and CPPs. [7] $\mathrm{QbD}$ reduces post approval regulatory submissions with design space development and facilitates novel approaches to process validation which is continuous process improvement and lifecycle management. [8]

Most of the review articles presented partial elements of $\mathrm{QbD}$ and articulation is missing for the application. This review article focuses on the $\mathrm{QbD}$ elements articulation along with supporting elements to achieve the quality products with design space. Current trends in the PAT applications are described along with unique application of QbD in product development. 


\section{Elements of Quality by Design (QbD)}

QbD encompasses following listed elements of pharmaceutical development. These elements will lead to the product with intended performance characteristics. Pharmaceutical development will provide a complete understanding of the product and its manufacturing process by application of QbD elements. [9]

- $\quad$ Quality target product profile (QTPP)

- Critical quality attributes (CQAs)

- Critical material attributes (CMAs)

- Critical process parameters (CPPs)

- Control strategy

- Product Lifecycle Management and Continual Improvement

Supporting elements including

- $\quad$ Risk assessment
- Design of Experiment (DoE)

- $\quad$ Process Analytical Technologies (PAT)

These elements are described in the following sections along with their articulation in product development.

\section{Quality Target Product Profile (QTPP)}

QTPP identification is the starting point for the product development. The US Food and Drug Administration (FDA) QbD initiative provides an enhanced assessment approach by introducing the concept of a QTPP. [10] QTPP is defined as, "A prospective summary of the quality characteristics of drug product that ideally will be achieved to ensure the desired quality, taking in to account safety \& efficacy of drug product." QTPP is not specification because it includes tests such as bioequivalence or stability that are not carried out in batch to batch release. Based on the clinical and pharmacokinetic characteristics as well as the in vitro dissolution and physicochemical characteristics of the reference product QTPP can be defined for the product. $[11,12]$ QTPP parameters for example Generic Acetriptan Tablets, 20 $\mathrm{mg}$ are presented in the below table 1. [13]

Table 1: Quality Target Product Profile (QTPP) parameters

\begin{tabular}{|c|c|c|c|}
\hline \multicolumn{2}{|c|}{ QTPP Elements } & Target & Justification \\
\hline \multicolumn{2}{|l|}{ Dosage form } & Tablet & $\begin{array}{l}\text { Pharmaceutical equivalence } \\
\text { requirement: same dosage form }\end{array}$ \\
\hline \multicolumn{2}{|l|}{ Dosage design } & $\begin{array}{l}\text { Immediate release tablet } \\
\text { without a score or coating }\end{array}$ & $\begin{array}{l}\text { Immediate release design needed } \\
\text { to meet label claims }\end{array}$ \\
\hline \multicolumn{2}{|c|}{ Route of administration } & Oral & $\begin{array}{l}\text { Pharmaceutical equivalence } \\
\text { requirement: same route of } \\
\text { administration }\end{array}$ \\
\hline \multicolumn{2}{|l|}{ Dosage strength } & $20 \mathrm{mg}$ & $\begin{array}{l}\text { Pharmaceutical equivalence } \\
\text { requirement: same strength }\end{array}$ \\
\hline \multicolumn{2}{|l|}{ Pharmacokinetics } & $\begin{array}{l}\text { Immediate release enabling } \\
\mathrm{T}_{\max } \text { in } 2.5 \text { hours or less; } \\
\text { Bioequivalent to RLD }\end{array}$ & $\begin{array}{l}\text { Bioequivalence requirement } \\
\text { Needed to ensure rapid onset and } \\
\text { efficacy }\end{array}$ \\
\hline \multicolumn{2}{|l|}{ Stability } & $\begin{array}{l}\text { At least } 24 \text {-month shelf-life at } \\
\text { room temperature }\end{array}$ & $\begin{array}{l}\text { Equivalent to or better than RLD } \\
\text { shelf-life }\end{array}$ \\
\hline \multirow{9}{*}{$\begin{array}{l}\text { Drug product } \\
\text { quality attributes }\end{array}$} & Physical Attributes & \multirow{9}{*}{\multicolumn{2}{|c|}{$\begin{array}{l}\text { Pharmaceutical equivalence requirement: Must meet the same } \\
\text { compendial or other applicable (quality) standards (i.e., identity, } \\
\text { assay, purity, and quality). }\end{array}$}} \\
\hline & Identification & & \\
\hline & Assay & & \\
\hline & Content Uniformity & & \\
\hline & Dissolution & & \\
\hline & Degradation Products & & \\
\hline & Residual Solvents & & \\
\hline & Water Content & & \\
\hline & Microbial Limits & & \\
\hline \multicolumn{2}{|c|}{ Container closure system } & $\begin{array}{l}\text { Container closure system } \\
\text { qualified as suitable for this } \\
\text { drug product }\end{array}$ & $\begin{array}{l}\text { Needed to achieve the target } \\
\text { shelf-life and to ensure tablet } \\
\text { integrity during shipping }\end{array}$ \\
\hline \multicolumn{2}{|c|}{ Administration/Concurrence with labeling } & Similar food effect as RLD & $\begin{array}{l}\text { RLD labeling indicates that a high } \\
\text { fat meal increases the AUC and } \\
C_{\max } \text { by } 8-12 \% \text {. The product can } \\
\text { be taken without regard to food. }\end{array}$ \\
\hline \multicolumn{2}{|c|}{ Alternative methods of administration } & None & None are listed in the RLD label. \\
\hline
\end{tabular}

Originator's product characteristic will be strictly used for defining the QTPP for the Biosimilar products. [14] Sterile Product QTPP may be unique in terms of need for administration devices and requirements specific to sterile products such as endotoxin limits. [15]
QTPP identification will be followed by CQAs identification based on the risk assessment. CQAs will be derived from the QTPP considering impact on the safety of the patients. 


\section{Critical Quality Attributes (CQAs)}

A Critical quality attribute (CQA) is "A physical, chemical, biological, or microbiological property or characteristic that should be within an appropriate limit, range, or distribution to ensure the desired product quality." CMAs and CPPs are identified during product development and are linked to the CQAs. Risk assessment process will be used to facilitate this evaluation. CQAs include but are not limited to Assay, Dissolution, Sterility, Degradation products and Crystallinity etc. $[16,17]$ Active Pharmaceutical Ingredient CQAs can also be controlled with QbD. [18]

Identification of the CQAs is followed by risk assessment of Active pharmaceutical ingredient and Formulation variables to arrive at the CMAs.

\section{Critical Material Attributes (CMAs)}

CMAs includes physical, chemical, biological, or microbiological properties or characteristics of an input material used in the product development. CMAs should be within an appropriate limit to ensure the desired quality of that drug substance, excipient or in-process material. Risk assessment process is used to derive the CMAs. $[19,20]$

Identification of the CMAs is followed by identification of the CPPs of the process used for the product manufacture with use of the risk assessment tools.

\section{Critical process parameters (CPPs)}

A process parameter is critical when a realistic change in that parameter can cause the product to fail to meet the QTPP. For example if development studies showed that the granulation was affected by realistic changes in impeller speed or granulation time then these should be identified as CPPs. Risk assessment process can lead to identification of the CPPs. Control strategies should be defined for the identified CPPs. CPPs are studied for their impact on the CQAs. Critical parameters of process and materials and their link with the product CQAs is presented in the following figure 1. [21, 22]

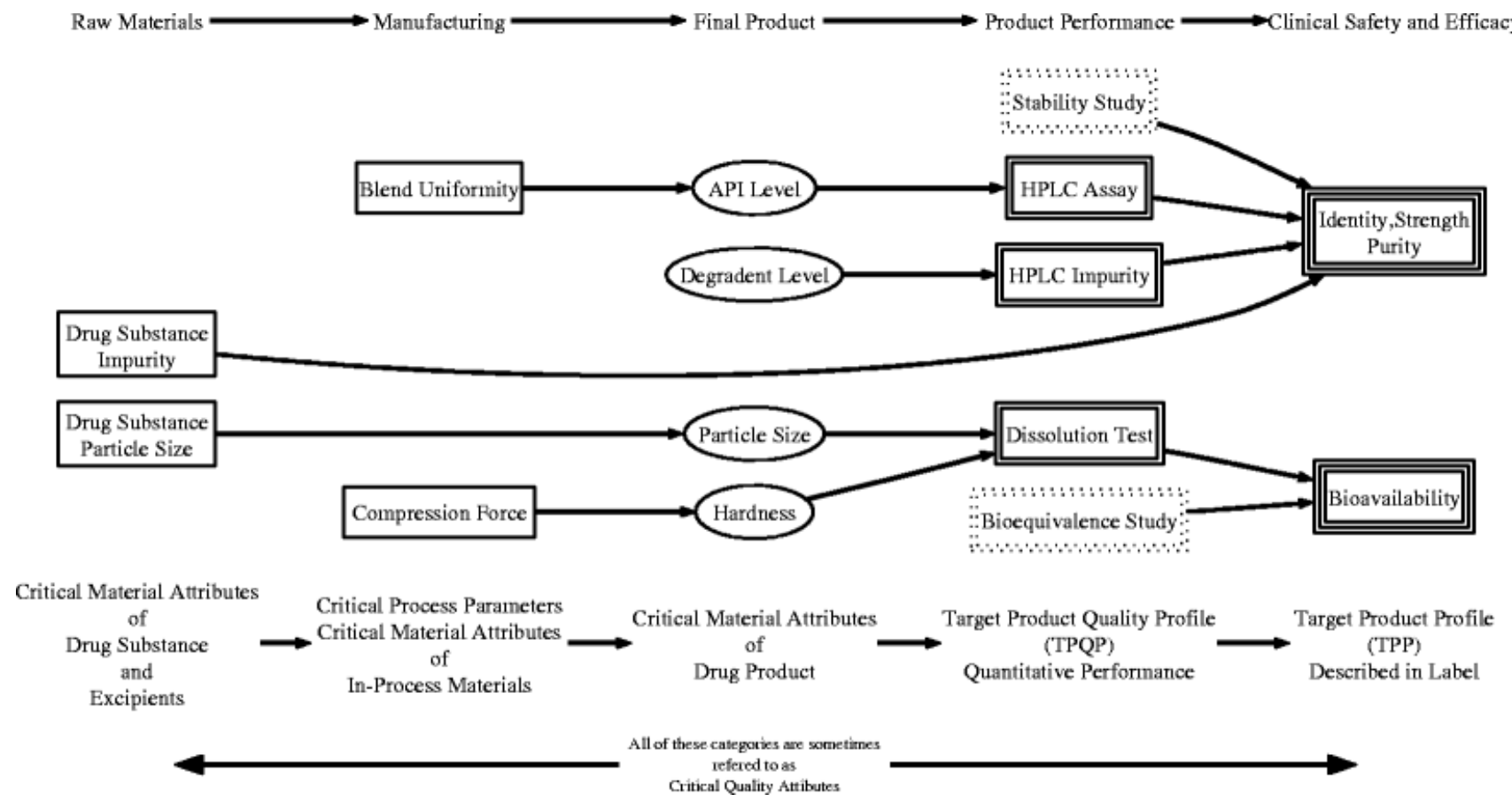

Figure 1: Critical parameters of process and materials with their link to CQAs

Resources can be utilized in the most critical areas with QbD process. Dossier with QbD compliant product development help FDA reviews decrease post-approval regulatory submissions required to make process changes. [23] Process modeling tools such as PAT can play a role in developing robust and economically efficient manufacturing processes. [24]

Based on the knowledge of the CMAs and CPPs and their link to the CQAs robust process development will be carried out. Formulation development trials at lab will be scaled to the Pilot or Production scale and Control strategies will be derived. DoE can be used for the experimentation of the CPPs and CMAs to study their impact on the CQAs to derive the design space.

\section{Control Strategy}

Control strategy is defined as "a planned set of controls, derived from current product and process understanding that assures process performance and product quality". Risk assessment is used to derive the Control strategy for the CQAs. The control strategy is derived for the procedural controls, in-process controls, lot release testing, process monitoring, characterization testing, comparability and stability testing. [25] A control strategy may include design spaces and final product specifications. Control strategy for the commercial scale will be proposed in the submission to FDA. [26]

Design space is designed for the product which will be verified by the regulatory agency. The Design Space encompasses the proven acceptable ranges for CMAs, CPPs and CQAs. Normal operating ranges are a part of the design space [27]. Risk assessment, experimental design along with the use of literature / prior experience can be leveraged to derive the design space for the product. [28] Material attribute design space is independent of scale and configuration of process equipment and the related process variables. Thus 
post-approval changes of equipment scale, nameplate, or location would not require any regulatory approval. [29]

Product submission will include the proposed product commercialization design space with QbD Product life cycle and continual improvement approach.

\section{Product Lifecycle Management and Continual Improvement}

Risk assessment throughout product development leads to robust product with less deviations. [30] Manufacturing process performance will be monitored to confirm that it is working within design space. Process capability and trend analysis will be performed. Continual improvement of the drug product will be performed with knowledge gained from the product. [31]

Supporting elements to achieve the product development with QbD application are Risk assessment, DoE and PAT. These tools are discussed in the following sections. These are integral part of the QbD.

\section{Risk assessment}

QRM principles are used to achieve the enhanced knowledge of the product. [32] Commonly used tools are Ishikawa diagram \& Failure Mode and Effects Analysis (FMEA). [33] QRM helps in identifying effect of CMAs and CPPs on CQAs. This risk assessment helps regulators to achieve the greater understanding of the product and leads to patient benefits. [34]

Risk assessment of the drug substance attributes performed to evaluate the impact that each attribute could have on the drug product CQAs. The outcome of the assessment and the accompanying justification is provided as a summary in the Pharmaceutical development report. The relative risk that each attribute presents was ranked as high, medium or low. The high risk attributes warranted further investigation whereas the low risk attributes required no further investigation. The medium risk is considered acceptable based on current knowledge. Further investigation for medium risk may be needed in order to reduce the risk. [35] Following figure 2 shows overview of a typical QRM process. $[36,37]$

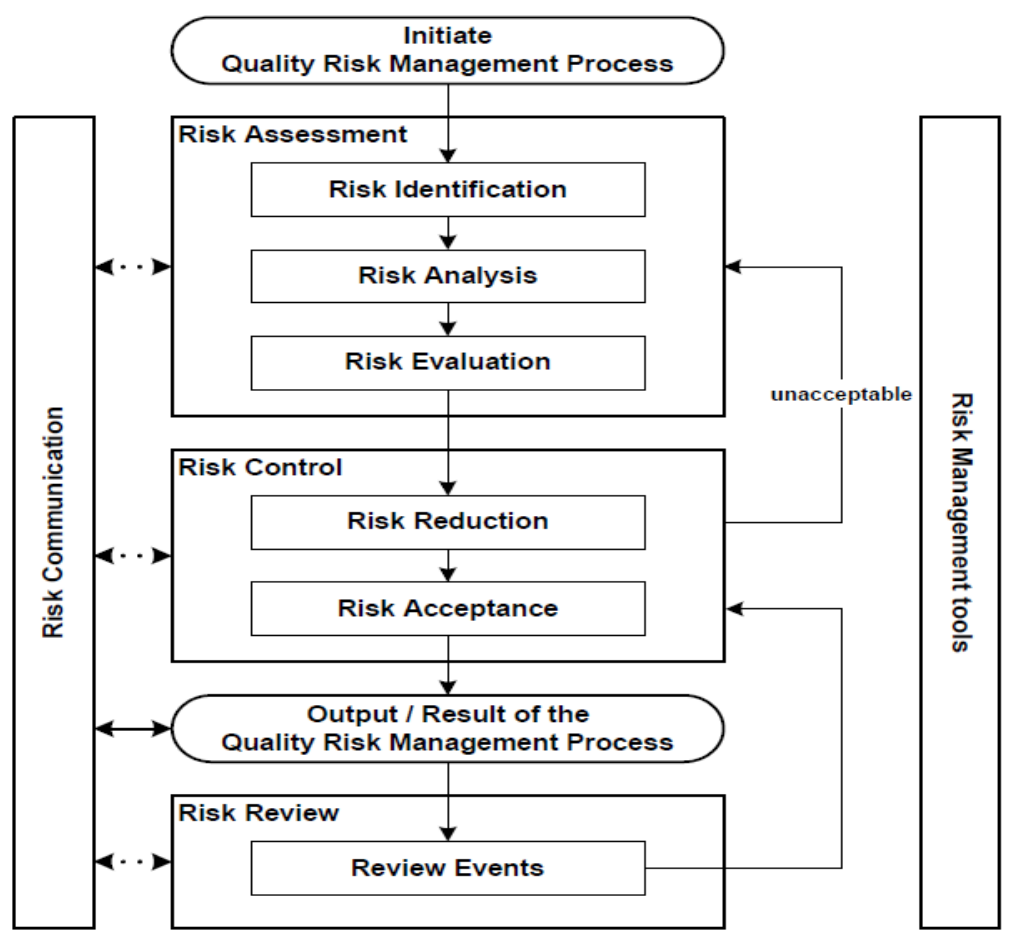

Figure 2: Overview of a typical QRM process

QRM process described above could help the oral Peptide delivery system development which has many formulation barriers. QRM helps to manage on the resources (human, financial \& time) related to the final product quality in more productive way. [38]

Identified CMAs and CPPs can be studied with DoE tools for their impact on CQAs to achieve design space.

\section{Design of Experiments (DoE)}

DoE process is used for the attribute interaction studies. Studies on CPPs and CMAs for their impact on the CQAs can be carried out with DoE to arrive the design space. This will lead to the product meeting CQAs and QTPP. [39] DoE studies can be carried out at lab scale or on pilot scale processes. [40] Legacy drug products are developed with application of
Multivariate statistical analysis and DoE to achieve design space. [41] QbD, PAT, real-time data generation and control monitoring systems knowledge will be better captured, managed and shared during product life cycle for product continuous improvements. [42]

\section{Process Analytical Technology (PAT)}

PAT tool can be used for the product development from early development to commercialization. FDA PAT Guidance and ICH Q8 suggest for the PAT tool utilization to monitor process online. $[43,44]$ PAT tools are classified as Multivariate Tools for Design, data acquisition and analysis, process analyzers, process control and continuous improvement and knowledge management. $[45,46]$ Current trends in the PAT tools application are described for product development. 
NIR spectroscopy is used in coating process, [47] Determination of content uniformity, compression force and crushing strength for Orbifloxacin tablets, Film coat curing and release monitoring, $[48,49,50]$ Monitoring blend potency and uniformity in the manufacturing of an oral solid dosage product. [51] PAT tools used for process monitoring and control tools that enables monitoring of real-time release. [52] Confocal Raman microscopy to study content uniformity and the polymorphic form of a drug substance distributed within a lipid based inhalable powder. [53] Additional application of NIR can include for design and scale-up of a batch mixing process, [54] Coating thickness monitoring for its impact on dissolution. [55] Thus PAT can support for QRM to arrive at design space. [56]

This discussion summarizes the articulation of the QbD elements in the product development. QbD process stars with QTPP and CQA identification. CMAs and CPPs are derived with risk assessment from the product understanding. Their impact on the CQAs can be studies with DoE tools. This will lead to identification of the control strategy and design space. Product process will be follow life cycle management approach with continuous improvement. PAT tools are utilized for the online monitoring of the processes. All this lead to robust product development.

Following literature reports of unique applications of $\mathrm{QbD}$ elements in different areas of Formulation development are summarized.

\section{Biotechnology}

\section{Protein Liposomes}

$\mathrm{Xu} \mathrm{X}$ et al. prepared Superoxide dismutase containing liposome formulations using freeze and thaw unilamellar vesicles followed by use of risk analysis and D-optimal statistical design resulting in liposomes with 6 months stability in aqueous dispersion state at $4^{\circ} \mathrm{C}$. [57]

\section{Monoclonal Antibody Product}

Nagashima $\mathrm{H}$ et al. used $\mathrm{QbD}$ for cell culture process of monoclonal antibody production resulting in the establishment of a design space with QRM. [58]

\section{Peptide Product}

Reihaneh Manteghi et al. prepared antimicrobial peptide modification and formulation design analyzed the potential risks in the antimicrobial Peptide PEGylation process. [59]

\section{Biosimilar product}

Rathore AS et al. studied development of a purification process for the production of a biosimilar product granulocyte colony-stimulating factor (GCSF) using QbD. [60]

\section{Topical Formulations}

Marto J et al. prepared starch based Nanocapsules formulation of lipophilic bioactive molecule for topical drug delivery and studies indicated a good physical stability, safety and cosmeticity. [61]

\section{Creams}

Mendonsa NS et al. formulated topical creams of Hydrocortisone acetate via hot melt extrusion technology coupled with a DoE approach to derive ideal product properties. [62]

\section{Transdermal products}

\section{Nanostructured lipid carriers}

Qian Kang et al. formulated and optimized Tripterine loaded in Nanostructured lipid carriers (NLCs) for transdermal delivery with emulsification evaporation method. Different drug administration methods and dermatokinetic study revealed the rapid lose water of gel could enhance NLCs into deep skin layer. [63]

\section{Transferosomes}

Fernández-García $\mathrm{R}$ et al. prepared Transferosomes as nanocarriers gel have shown promising results in the alleviation of symptons in orthreothritis with non-severe skin and subcutaneous tissue disorders. [64]

\section{Ethosomes}

Jain S et al. formulated ethosome of Diclofenac for enhanced anti-inflammatory activity using $4 \times 5$ full-factorial design with Phosphatidylcholine \& Cholesterol and studied skin permeation kinetics. [65]

\section{Nanotechnology based products \\ Nanoparticles}

Park SY et al. formulated Sorafenib loaded Nanoparticles with Fat and supercritical fluid (NUFS ${ }^{\mathrm{TM}}$ ) to improve oral bioavailability and In vivo pharmacokinetics studies in beagle dogs demonstrated that optimized formulation of Sorafenib exhibited higher blood drug profiles indicating better absorption compared to the reference tablet (Nexavar@). [66]

Yerlikaya $\mathrm{F}$ et al. developed and characterized Paclitaxel Nanoparticles with Ishikawa diagram risk assessment and screened by Plackett Burman design and finally Nanoparticles were optimized using Box Behnken design. In vitro cytotoxicity test showed that the developed Nanoparticles are more efficient than free Paclitaxel in terms of antitumor activity. [67]

\section{Nanostructured lipid carrier}

Gurumukhi VC et al. fabricated Nanostructured lipid carrier (NLC) encapsulating Efavirenz explored characterizations and in vivo safety resulting high drug encapsulated potential nanocarrier to enhance bioavailability and confirms safety with promising acceptable criteria. [68]

\section{Nanoliposomes}

Mahtab A et al. formulated Teriflunomide loaded Nanoliposomes prepared with Thin-film hydration technique for treatment of Rheumatoid arthritis. In vivo pharmacokinetic study results revealed sustained release profile with higher therapeutic efficacy of the drug at the inflammatory site compared with Teriflunomide solution. [69]

\section{Nanosuspension}

Verma $S$ et al. studied process of Nanosuspension preparation with Multiple linear regression analysis and ANOVA to create design space and designed model the process of Microfluidization for predictive purposes. [70]

\section{Nanoemulsion}

Negi $P$ et al. formulated biocompatible Lidocaine and Prilocaine loaded Nanoemulsion system for enhanced percutaneous absorption and superior permeation rates with higher concentrations of the drugs in skin layers from the optimised formulations when compared to marketed cream. [71] 


\section{Inhalation products}

\section{Microparticles}

Zhang L et al. optimized Budesonide loaded large porous Microparticles for Inhalation drug delivery. [72]

\section{Dry powder inhalers}

Buttini F et al. studies development of Dry powder inhalers with QbD framework. [73]

\section{Nasal Products}

Bartos C et al. formulated Levodopa containing Dry powder for Nasal delivery. Based on risk assessment, Levodopa and Chitosan or Sodium hyaluronate as mucoadhesive matrix formers were co-milled using planetary ball mill to prepare Microparticles as drug delivery systems. [74]

\section{Injectable Formulations}

\section{Lipid injectable emulsion}

Deng Y et al. prepared fat soluble vitamins Lipid injectable emulsion \& design space was obtained with DoE. Safety of the optimal emulsion was evaluated as acceptable through the determination of lysophospholipid content and an in vitro hemolysis assay. [75]

\section{Lyophilized liposomes}

Porfire A et al. developed lyophilized Liposomes with Simvastatin to increase shelf-life of Liposomes with Design space. [76]

\section{Self Nanoemulsified Drug Delivery System (SNEDDS)}

Zidan AS et al. studied product variability of a SNEDDS of Cyclosporine A \& demonstrated the ability to understand the impact of nanodroplets size on the SNEDDS variability (Size) by different product analyzing tools such as Near Infrared (NIR) and Chemometric analysis. [77]

\section{Targeted Drug Delivery}

\section{Microspheres for colon-specific delivery}

Hales D et al. formulated Enoxaparin sodium loaded polymeric Microspheres for colon-specific delivery then CPPs and CQAs were identified and achieved design space. [78]

\section{Bone targeting therapeutic Radiopharmaceutical}

Lange R et al. prepared small scale process for Rhenium 188 HEDP which is a therapeutic Radiopharmaceutical for treatment of Osteoblastic bone metastases for bone targeting. The effect of CPPs on product quality and stability of 188Re-HEDP was studies. [79]

\section{Limicubes}

Javed MN et al. developed and optimized Bicontinuous cuboidal shaped Mucoadhesive Microcrystalline delivery systems (Limicubes) for oral delivery of Rosuvastatin. [80]

\section{Solid Oral products}

\section{Bilayer combination tablet}

Ah Ram Lee et al. optimized formulation of a bilayer combination tablet Telmisartan and Amlodipine besylate (Telmiduo®) manufactured via high shear wet granulation and showed greater physical stability along with in-vivo equivalence. [81]

\section{Controlled Release product}

Saurí J et al. studied physicochemical phenomena involved in Controlled release of Captopril matrix tablets with DoE. [82]

\section{Pellets}

Wang J et al. developed Naproxen loaded core pellets for Colon specific pellets and used Plackett Burman design to screen potential high risk factors. [83]

\section{Fluid bed granulation}

Lourenço V et al. studied industrial Pharmaceutical fluid bed granulation with QbD.[84]

\section{Spray drying}

Baldinger A et al. optimized Spray drying process with DoE. Non-invasive NIR measurement was used for correlating the CQA particle size with size determined by laser diffraction. [85]

\section{Roller Compaction}

Hsu SH et al. studied modeling and control of Roller compaction for pharmaceutical manufacturing with DoE. [86]

\section{High drug load tablet}

Sun CC et al. developed high drug load tablet formulation based on assessment of powder manufacturability for novel drug AMG458. [87]

\section{Tablet with artificial intelligence}

Aksu B et al. applied Artificial intelligence techniques to control the CQAs of Ramipril tablets manufactured by wet granulation and design space was derived using DoE with Artificial neural networks (ANNs). [88]

\section{Bioavailability Enhancement}

Chauhan MK et al. performed bioavailability enhancement of Polymyxin B with novel drug delivery Niosomes as carrier system. Formulation showed promising results in vitro antifungal, rat creatinine and cytotoxicity assay. [89]

\section{Dissolution Enhancement}

Parmar $\mathrm{K}$ et al. improved dissolution properties of poorly water soluble herbal active ingredient Embelin by formulating Liquisolid systems and optimized formulation with DoE. [90]

\section{Scale up}

\section{Coating process}

Agrawal AM et al. reviewed Scale up of pan coating process with DoE and PAT tool. [91]

\section{Orodispersible films}

Bülbül EO et al. showed improvement has been achieved for schizophrenic patients by the production of Quetiapine fumarate loaded Orodispersible films and the process of scale up in films has been demonstrated. [92]

\section{Analytical QbD}

\section{UV spectrophotometric method}

Kualiti MP et al. developed a robust UV spectrophotometric method for estimation of Vilazodone and showed that Sampling interval and slit width were the two influential Critical method variables which require special attention by the analyst while setting up the method control strategies and future experimentations for continual improvement in method performance. [93] 


\section{High Performance liquid chromatography (HPLC)}

Moreira CS et al. developed and optimized stabilityindicating Chromatographic method for Verapamil hydrochloride and its impurities in Tablets using an Analytical Quality by Design (AQbD) approach. [94]

\section{Ultrafast liquid chromatography}

Panda SS et al. studies Ultrafast liquid chromatography for estimation of hallucinogenic agents in drug products, drug in microdialysis samples, and drugs in skin diffusate samples. [95]

\section{Ultrahigh performance liquid chromatography}

Alexander H. Schmidt et al. developed a stability indicating UHPLC method for Ebastine in the API and pharmaceutical formulations and established model for Design Space is accurate. [96]

\section{Liquid chromatography-Tandem Mass spectrometry method}

Pasquini B et al. developed a Liquid chromatographyTandem Mass spectrometry method for the determination of Nintedanib and its impurities. Critical method parameters (CMPs) and critical method attributes (CMAs) were studied with DoE. [97]

\section{Tristimulus Colorimetry}

Hetrick EM et al. studies on Integrating Tristimulus Colorimetry into pharmaceutical development for color selection and physical appearance with QbD. [98]

\section{Capillary electrophoresis}

Orlandini S et al. developed a Capillary electrophoresis method for the analysis of Zolmitriptan and its impurities. DoE study was conducted to achieve the Design space. [99]

\section{Extractables \& Leachables Assessment}

Jenke D et al. studied Extractables \& Leachables assessment \& establishing a design space for terminally sterilized aqueous drug products stored in a plastic packaging system. [100]

\section{API manufacture}

AM Ende D et al. studied Torcetrapib manufacturing process with application of risk assessment, multivariate design and a proposed criticality assessment all of which coalesce into an design space. [101]

\section{Conclusion}

This review articulated the whole QbD process for product development. QbD process starts with QTPP and CQA identification. CMAs and CPPs are derived with risk assessment. Their impact on the CQAs can be studies with DoE tools. The information and knowledge gained from pharmaceutical development studies and manufacturing experience provide scientific understanding to support the design space and control strategy. Product process will be follow life cycle management approach with continuous improvement. PAT tools are utilized for the online monitoring of the processes. Unique applications of $\mathrm{QbD}$ in the various areas of the product development such as Biotechnology, Nanotechnology products, Nasal products, Inhalation, Injectable products, Targeted drug delivery, complex Solid oral, Transdermal and topical products, Bioavailability and dissolution enhancement, Analytical processes and API manufacturing etc. are described for easy industrial adoption. PAT tools are becoming increasingly famous for the online testing applications of the product thus current trend applications are described. Outcome of $\mathrm{QbD}$ product development will be a robust product development and product submission will lead to the less regulatory post approval queries on the changes during product life cycle management and continuous improvement of the process.

Funding: Nil

\section{Authors Contributions}

All authors have contributed equally.

\section{Conflict of Interests}

\section{Declared none}

\section{REFERENCES}

1. Roy S. Quality by design: A holistic concept of building quality in pharmaceuticals. Int J Pharm Biomed Res 2012; 3(2):100-8.

2. Yu LX. Pharmaceutical Quality by Design: Product and Process Development, Understanding and Control. Pharm Res 2008; 25:781-791.

3. Lawrence XY, Gregory A, Khan MA, Hoag SW, Polli J, Raju GK et al. Understanding Pharmaceutical Quality by Design. AAPS J 2014; 16(4):771-783.

4. Vemuri PN, Gupta V. A. Review on quality by design approach (QBD) for Pharmaceuticals. Int J Drug Dev Res 2015; 7(1):52-60.

5. Sangshetti JN, Deshpande M, Zaheer Z, Shinde DB, Arote R. Quality by design approach: Regulatory need. Arab J Chem 2017; 10:S3412-S3425.

6. Pramod K, Tahir MA, Charoo NA, Ansari SH, Ali J. Pharmaceutical product development: A quality by design approach. Int J Pharma Investig 2016; 6:29-138.

7. Rathore AS. Roadmap for implementation of quality by design (QbD) for biotechnology products. Trends Biotechnol 2009; 27(9):546-553.

8. Eziokwu NV. Quality by design (QbD): Manufacturing and product quality of generics drugs perspective. J Global Trends Pharm Sci 2013; 4(4):1257-62.

9. Fukuda IM, Pinto CF, Moreira CD, Saviano AM, Lourenço FR. Design of Experiments (DoE) applied to pharmaceutical and analytical Quality by Design (QbD). Braz J Pharm Sci 2018; 54.

10. Raw AS, Lionberger R, Lawrence XY. Pharmaceutical equivalence by design for generic drugs: modified-release products. Pharm Res 2011; 28(7):1445-53.

11. Chavan SD, Pimpodkar NV, Kadam AS, Gaikwad PS. Quality by Design. Journal of Pharmaceutical Quality Assurance 2015; 1(2):18-24.

12. Anuj G, Fuloria DN. Short review on Quality by design: A new Era of Pharmaceutical drug development. Int J Pharm Pharm Sci 2012; 4(3):19-26.

13. Jain S. Quality by design (QBD): A comprehensive understanding of implementation and challenges in pharmaceuticals development. Int J Pharm Pharm Sci 2014; 6:29-35.

14. Zalai D, Dietzsch C, Herwig C. Risk-based process development of biosimilars as part of the quality by design paradigm. PDA J Pharm Sci Tech 2013 Nov 1; 67(6):569-80.

15. Lambert WJ. Considerations in developing a target product profile for parenteral pharmaceutical products. AAPS Pharm Sci Tech 2010 Sep 1; 11(3):1476-81.

16. Kalyan A, Parle A. Quality by Design: Changing outlook of Pharmaceutical development Search Results. Int J Pharm Sci Res 2019; 10(9):4100-4108.

17. Mesut B, Özsoy Y, Aksu B. The place of drug product critical quality parameters in quality by design (QbD). Turk J Pharm Sci 2015; 12(1):75-92.

18. Mohammed AQ, Sunkari PK, Srinivas P, Roy AK. Quality by design in action 1: controlling critical quality attributes of an active pharmaceutical ingredient. Org Process Res Dev 2015; 19(11):1634-44

19. Zhang L, Mao S. Application of quality by design in the current drug development. Asian J Pharm Sci 2017;12:1-8

20. Chordiya MA, Gangurde HH, Sancheti VN. Quality by design: A Roadmap for quality pharmaceutical products. J Rep Pharm Sci 2019; 8:289-94.

21. Lionberger RA, Lee SL, Lee LM, Raw A, Lawrence XY. Quality by Design: Concepts for ANDAs. AAPS J 2008; 10(2):268-276. 
22. Nadpara NP, Thumar RV, Kalola VN, Patel PB. Quality by Design (QbD): A Complete Review. Int J Pharm Sci Rev Res 2012; 17(2):20-28.

23. Nagar M, Panwar KS, Chopra VS, Bala I, Trivedi P. Quality by design: a systematic approach to pharmaceutical development. Der Pharmacia Lettre 2010;2(2):111-30.

24. Rogers A, Ierapetritou M. Challenges and opportunities in modeling pharmaceutical manufacturing processes. Comput Chem Eng 2015; 81:32-9.

25. Patil AS, Pethe AM. Quality by Design (QbD): A new concept for development of quality pharmaceuticals. International Journal of Pharmaceutical Quality Assurance 2013; 4(2):13-19.

26. Bendale HP, Bakliwal AA, Talele SG, Deshmukh SA, Chaudhari GN. Quality by Design: A Modern approach in Pharmaceutical development of Formulation. World J Pharm Res 2015; 4(3):402-422.

27. Sumit K, Shikha T, Deepika T, Ashish B. A quantitative approach for pharmaceutical quality by design patterns. Inveti Rapid: Pharm Anal Qual Assur 2012; (4):1-8.

28. Garcia T, Cook G, Nosal R. PQLI key topics-criticality, design space, and control strategy. J Pharm Innov 2008; 3(2):60-8.

29. Michaels JN, Bonsignore $\mathrm{H}$, Hudson-Curtis BL, Laurenz S, Lin HR, Mathai T, Pande G, Sheth A, Sprockel O. Attribute-based design space: materials-science-based quality-by-design for operational flexibility and process portability. I Pharm Innov 2011; 6(4):193-201.

30. Jadhav JB, Girawale NN, Chaudhari RA. Quality by Design (QBD) Approach used in Development of Pharmaceuticals. Int J Pure App Biosci 2014; 2(5):214-223.

31. Tambe K, Bonde S. A review on: Applications of pharmaceutical quality by design in product development. World J Pharm Sci 2017; 5(1):58-70.

32. Elliott P, Billingham S, Bi J, Zhang H. Quality by design for biopharmaceuticals: a historical review and guide for implementation. Pharm Bioprocess 2013; 1(1):105-22.

33. Grangeiaab HB, Silvaa C, Simõesab SP, Marco S. Quality by design in pharmaceutical manufacturing: A systematic review of current status, challenges and future perspectives. Eur J Pharm Biopharm 2020; 147:9-37.

34. Udugade SB, Udugade BV, Mandhare TA. Pharmaceutical Quality by Design: A Hopeful Ray for Quality Product. Int J Med Pharm Res 2016; 4(5):297-300.

35. International Conference on Harmonisation of Technical Requirements for Registration of Pharmaceuticals for Human Use (ICH), ICH Harmonised Tripartite Guideline, Pharmaceutical Development, Q8(R2), 2009.

36. Purohit PJ, Shah KV. Quality by Design (QbD): New parameter for quality improvement \& pharmaceutical drug development. Pharm Sci Monitor 2013; 3(3).

37. Hulbert MH, Feely LC, Inman EL, Johnson AD, Kearney AS, Michaels J, Mitchell M, Zour E. Risk management in the pharmaceutical product development process. J Pharma Innov 2008; 3(4):227-48.

38. Pallagi E, Ismail R, Paal TL, Csóka I. Initial risk assessment as part of the quality by design in peptide drug containing formulation development. Eur J Pharm Sci 2018; 122:160-9.

39. Politis N, Colombo P, Colombo G, M. Rekkas D. Design of experiments (DoE) in pharmaceutical development. Drug Dev Ind Pharm 2017; 43(6):889-901.

40. Patel H, Parmar S, Patel B. A Comprehensive Review on Quality by Design (QbD) in Pharmaceuticals. Int J Pharm Sci Rev Res 2013; 21(1):223-236.

41. Yacoub F, Lautens J, Lucisano L, Banh W. Application of quality by design principles to legacy drug products. J Pharm Innov 2011; 6(2):61.

42. International Conference on Harmonisation of Technical Requirements for Registration of Pharmaceuticals for Human Use (ICH), Quality Implementation Working Group on Q8, Q9 and Q10 Questions \& Answers (R4), 2010.

43. Ferreira AP, Tobyn M. Multivariate analysis in the pharmaceutical industry: enabling process understanding and improvement in the PAT and QbD era. Pharm Dev Tech 2015; 20(5):513-27.

44. Murphy T, O'Mahony N, Panduru K, Riordan D, Walsh J. Pharmaceutical manufacturing and the quality by design (QBD), process analytical technology (PAT) approach. $201627^{\text {th }}$ Irish Signals and Systems Conference. IEEE. 1-7.
45. U.S. Department of Health and Human Services Food and Drug Administration, Guidance for Industry, PAT-A Framework for Innovative Pharmaceutical Development, Manufacturing, and Quality Assurance 2004.

46. McKenzie P, Kiang S, Tom J, Rubin AE, Futran M. Can pharmaceutical process development become high tech?. AIChE Journal 2006; 52(12):3990-4.

47. Lee SL, O'Connor TF, Yang X, Cruz CN, Chatterjee S, Madurawe RD, Moore CM, Lawrence XY, Woodcock J. Modernizing pharmaceutical manufacturing: from batch to continuous production. J Pharm Innov 2015; 10(3):191-9.

48. Tabasi SH, Fahmy R, Bensley D, O'Brien C, Hoag SW. Quality by design, part I: Application of NIR spectroscopy to monitor tablet manufacturing process. J Pharm Sci 2008; 97(9):4040-51.

49. Tabasi SH, Fahmy R, Bensley D, O'Brien C, Hoag SW. Quality by design, part II: application of NIR spectroscopy to monitor the coating process for a pharmaceutical sustained release product. J Pharm Sci 2008; 97(9):4052-66.

50. Tabasi SH, Fahmy R, Bensley D, O'Brien C, Hoag SW. Quality by design, part III: study of curing process of sustained release coated products using NIR spectroscopy. J Pharm Sci 2008; 97(9):4067-86.

51. Corredor CC, Lozano R, Bu X, McCann R, Dougherty J, Stevens T, Both D, Shah P. Analytical method quality by design for an online near-infrared method to monitor blend potency and uniformity. J Pharm Innov 2015; 10(1):47-55.

52. Somma R. Development knowledge can increase manufacturing capability and facilitate quality by design. J Pharm Innov 2007; 2(3-4):87-92.

53. Schoenherr C, Haefele T, Paulus K, Francese G. Confocal Raman microscopy to probe content uniformity of a lipid based powder for inhalation: a quality by design approach. Eur J Pharm Sci 2009; 38(1):47-54

54. Portillo PM, Ierapetritou M, Tomassone S, Mc Dade C, Clancy D, Avontuur PP, Muzzio FJ. Quality by design methodology for development and scale-up of batch mixing processes. J Pharm Innov 2008; 3(4):258-70.

55. Lee MJ, Seo DY, Lee HE, Wang IC, Kim WS, Jeong MY, Choi GJ. In line NIR quantification of film thickness on pharmaceutical pellets during a fluid bed coating process. International journal of pharmaceutics 2011; 403(1-2):66-72.

56. Hertrampf A, Müller H, Menezes JC, Herdling T. A PAT-based qualification of pharmaceutical excipients produced by batch or continuous processing. J Pharmaceut Biomed 2015; 114:208-15.

57. Xu X, Costa AP, Khan MA, Burgess DJ. Application of quality by design to formulation and processing of protein liposomes. Int J Pharm 2012; 434(1-2):349-59.

58. Nagashima H, Watari A, Shinoda Y, Okamoto H, Takuma S. Application of a quality by design approach to the cell culture process of monoclonal antibody production, resulting in the establishment of a design space. J Pharma Sci 2013; 102(12):4274-83.

59. Manteghi R, Pallagi E, Olajos G, Csóka I. Pegylation and formulation strategy of Anti-Microbial Peptide (AMP) according to the quality by design approach. Eur J Pharm Sci 2019. Doi: https://doi.org/10.1016/j.ejps.2019.105197

60. Rathore AS. Quality by design (QbD)-based process development for purification of a biotherapeutic. Trends in biotechnology. 2016; 34(5):358-70.

61. Marto J, Gouveia LF, Gonçalves LM, Gaspar DP, Pinto P, Carvalho FA, Oliveira E, Ribeiro HM, Almeida AJ. A quality by design (QbD) approach on starch-based nanocapsules: a promising platform for topical drug delivery. Colloid Surf B. 2016; 143:177-85.

62. Nicole S. Mendonsa, Adwait Pradhan, Purnendu Sharma, Rosa M.B. Prado, S. Narasimha Murthy, Santanu Kundu et al. A quality by design approach to develop topical creams via hot-melt extrusion technology. Eur J Pharm Sci 2019. Doi: https://doi.org/10.1016/j.ejps.2019.06.002

63. Qian Kang, Jia Liu, Xin-Yan Liu, Nuo-Lan Mo, Yong-Jie Wang, Ying Zhao et al. Application of quality by design approach to formulate and optimize Tripterine loaded in nanostructured lipid carriers for transdermal delivery. J Drug Deliv Sci Tec 2019; 52:1032-1041.

64. Raquel Fernández-García, Aikaterini Lalatsa, Larry Statts, Francisco Bolás-Fernández, M. Paloma Ballesteros, Dolores R. Serrano. Transferosomes as nanocarriers for drugs across the skin: Quality by design from lab to industrial scale. Int J Pharm 2020. Doi: https://doi.org/10.1016/j.ijpharm.2019.118817 
65. Jain S, Patel N, Madan P, Lin S. Quality by design approach for formulation, evaluation and statistical optimization of Diclofenac-loaded Ethosomes via transdermal route. Pharm Dev Tech. 2015; 20(4):473-89.

66. Park SY, Kang Z, Thapa P, Jin YS, Park JW, Lim HJ et al. Development of Sorafenib loaded nanoparticles to improve oral bioavailability using a quality by design approach. Int J Pharm 2019; 566:229-238.

67. Yerlikaya F, Ozgen A, Vural I, Guven O, Karaagaoglu E, Khan MA, Capan Y. Development and evaluation of Paclitaxel nanoparticles using a quality-by-design approach. J Pharm Sci 2013; 102(10):3748-61.

68. Gurumukhi VC, Bari SB. Fabrication of Efavirenz loaded nanoformulation using quality by design (QbD) based approach: Exploring characterizations and in vivo safety. J Drug Deliv Sci Tec 2020. Doi: https://doi.org/10.1016/j.jddst.2020.101545

69. Mahtab A, Md. Rizwanullah, Pandey S, Leekha A, Rabbani SA, Verma A et al. Quality by design driven development and optimization of Teriflunomide loaded Nanoliposomes for treatment of rheumatoid arthritis: An in vitro and in vivo assessments. J Drug Deliv Sci Tec 2019; 51:383-396.

70. Verma S, Lan Y, Gokhale R, Burgess DJ. Quality by design approach to understand the process of Nanosuspension preparation. Int J Pharm Volume 2009;377(1-2):185-198.

71. Negi P, Singh B, Sharma G, Beg S, Katare OP. Biocompatible Lidocaine and Prilocaine loaded-nanoemulsion system for enhanced percutaneous absorption: QbD-based optimisation, dermatokinetics and in vivo evaluation. J Microencapsul 2015;32(5):419-31.

72. Zhang L, Zhang X, Li J, Broichsitter MB, Muenster U, Wang X et al. Optimization of Budesonide-loaded large-porous microparticles for inhalation using quality by design approach. J Drug Deliv Sci Tec 2019. Doi: https://doi.org/10.1016/j.jddst.2019.101140.

73. Buttini F, Rozou S, Rossi A, Zoumpliou V, Rekkas DM. The application of quality by design framework in the pharmaceutical development of Dry powder inhalers. Eur J Pharm Sci 2018; 113:64-76.

74. Bartos C, Pallagi E, Szabó-Révész P, Ambrus R, Katona G, Kiss T, Rahimi M, Csóka I. Formulation of Levodopa containing dry powder for nasal delivery applying the quality-by-design approach. Eur J Pharm Sci 2018; 123:475-483.

75. Deng Y, Zhong G, Wang Y, Wang N, Yu Q, Yu X. Quality by design approach for the preparation of Fat-soluble vitamins lipid injectable emulsion. Int J Pharm 2019. Doi: https://doi.org/10.1016/j.ijpharm.2019.118717

76. Porfire A, Muntean DM, Rus L, Sylvester B, Tomuță I. A quality by design approach for the development of lyophilized liposomes with Simvastatin. Saudi Pharm J 2017; 25(7):981-992.

77. Zidan AS, Sammour OA, Hammad MA, Megrab NA, Habib MJ, Khan MA. Quality by design: understanding the product variability of a Self-nanoemulsified drug delivery system of cyclosporine A. J Pharm Sci 2007; 96(9):2409-23.

78. Hales D, Vlase L, Porav SA, Bodoki A, Barbu-Tudoran L, Achim M, Tomuță I. A quality by design (QbD) study on Enoxaparin sodium loaded polymeric microspheres for colon-specific delivery. Eur J pharm Sci 2017; 100:249-61.

79. Lange R, Ter Heine R, Van Der Gronde T, Selles S, De Klerk J, Bloemendal $\mathrm{H}$, Hendrikse $\mathrm{H}$. Applying quality by design principles to the small-scale preparation of the bone-targeting therapeutic radiopharmaceutical Rhenium-188-HEDP. Eur Pharm Sci 2016; 90:96-101.

80. Javed MN, Kohli K, Amin S. Risk assessment integrated QbD approach for development of optimized bicontinuous mucoadhesive limicubes for oral delivery of Rosuvastatin. AAPS Pharm Sci Tech 2018; 19(3):1377-91.

81. Lee AR, Kwon SY, Choi DH, Park ES. Quality by Design (QbD) approach to optimize the formulation of a bilayer combination tablet (Telmiduo®) manufactured via high shear wet granulation. Int J Pharm 2017; 534(1-2):144-158.

82. Saurí J, Millán D, Suñé-Negre JM, Colom H, Ticó JR, Miñarro M, Pérez-Lozano P, García-Montoya E. Quality by Design approach to understand the physicochemical phenomena involved in controlled release of Captopril SR matrix tablets. Int J Pharm 2014; 477(1-2):431-441.

83. Wang J, Kan S, Chen T, Liu J. Application of quality by design (QbD) to formulation and processing of Naproxen pellets by extrusion-spheronization. Pharm Dev Tech 2015; 20(2):246-56.
84. Lourenço V, Lochmann D, Reich G, Menezes JC, Herdling T, Schewitz J. A quality by design study applied to an industrial pharmaceutical fluid bed granulation. Eur J Pharm Biopharm 2012; 81(2):438-447.

85. Baldinger A, Clerdent L, Rantanen J, Yang M, Grohganz H. Quality by design approach in the optimization of the spray-drying process. Pharm Dev Technol 2012;17(4):389-97.

86. Hsu SH, Reklaitis GV, Venkatasubramanian V. Modeling and control of roller compaction for pharmaceutical manufacturing. Part I: Process dynamics and control framework. J Pharm Innov 2010; 5(1-2):14-23.

87. Sun CC, Hou H, Gao P, Ma C, Medina C, Alvarez FJ. Development of a high drug load tablet formulation based on assessment of powder manufacturability: moving towards quality by design. Pharm Sci 2009; 98(1):239-47.

88. Aksu B, Paradkar A, de Matas M, Özer Ö, Güneri T, York P. A quality by design approach using artificial intelligence techniques to control the critical quality attributes of Ramipril tablets manufactured by wet granulation. Pharm Dev Technol 2013; 18(1):236-45.

89. Meenakshi K. Chauhan, Nidhi Bhatt. Bioavailability Enhancement of Polymyxin B With Novel Drug Delivery: Development and Optimization Using Quality-by-Design Approach. J Pharm Sci 2019; 108(4):1521-1528.

90. Parmar K, Patel J, Sheth N. Formulation and development of Embelin liquisolid systems using quality by design approach. J Pharm Investig 2016; 46(6):547-56.

91. Agrawal AM, Pandey P. Scale up of pan coating process using quality by design principles. J Pharm Sci 2015; 104(11):3589611.

92. Bülbül EO, Mesut B, Cevher E, Öztaş E, Özsoy Y. Product transfer from lab-scale to pilot-scale of quetiapine fumarate orodispersible films using quality by design approach. J Drug $\begin{array}{llll}\text { Deliv } & \text { Sci } & \text { Tec } & 2019 .\end{array}$ https://doi.org/10.1016/j.jddst.2019.101358

93. Kualiti MP. Spectrophotometric quantification of Vilazodone hydrochloride in pharmaceutical dosage form using quality by design approach. Malaysian Journal of Analytical Sciences 2015; 19(5):920-9.

94. Moreira CS, Lourenço FR. Development and optimization of a stability-indicating chromatographic method for Verapamil hydrochloride and its impurities in tablets using an analytical quality by design (AQbD) approach. Microchem J 2020. Doi: https://doi.org/10.1016/j.microc.2020.104610

95. Panda SS, Bera VV, Beg S, Sahu SK. Ultrafast liquid chromatographic method development and its validation for quantification of Telaprevir in pharmaceutical dosage form by using quality by design approach. J Chromatogr Sci 2015; 53(7):1193-202

96. Schmidt AH, Molnár I. Using an innovative Quality-by-Design approach for development of a stability indicating UHPLC method for Ebastine in the API and pharmaceutical formulations. J Pharm Biomed Anal 2013; 78-79:65-74.

97. Pasquini B, Orlandini S, Furlanetto S, Gotti R, Bubba MD, Boscaro $\mathrm{F}$ et al. Quality by Design as a risk-based strategy in pharmaceutical analysis: Development of a Liquid chromatography-Tandem mass spectrometry method for the determination of Nintedanib and its impurities. J Chromatogr A 2020. Doi: https://doi.org/10.1016/j.chroma.2019.460615

98. Hetrick EM, Vannoy J, Montgomery LL, Pack BW. Integrating Tristimulus colorimetry into pharmaceutical development for color selection and physical appearance control: a quality-bydesign approach. J Pharm Sci 2013; 102(8):2608-21.

99. Orlandini S, Pasquini B, Caprini C, Del Bubba M, Pinzauti S, Furlanetto S. Analytical Quality by Design in pharmaceutical quality assurance: Development of a capillary electrophoresis method for the analysis of Zolmitriptan and its impurities. Electrophoresis 2015; 36(21-22):2642-9.

100. Jenke D. Application of quality by design (QbD) principles to Extractables / Leachables assessment. Establishing a design space for terminally sterilized aqueous drug products stored in a plastic packaging system. PDA J Pharm Sci Technol 2010; 64(6):527-35.

101. Ende D, Bronk KS, Mustakis J, O'Connor G, Santa Maria CL, Nosal R, Watson TJ. API quality by design example from the Torcetrapib manufacturing process. Journal of Pharmaceutical Innovation 2007; 2(3-4):71-86. 